half inch diameter, the other for irrigation being of small size, and about two foet in length; these were inserted into the cavity. Scarcely had this been done, and it was done carefully and without difficulty, when alarming hxmorrhago set in. As speedily as possible I irrigated with very hot water, with the result that bleeding stopped before serious loss had been sustained; thereafter pieces of absorbent cotton soaked in sublimate solution were packed round the tubes in the wound, and outside it. This dressing was retained in position by a T-bandage, to which, also, the tubes were secured. I omit details of the method of drainage, except such as are necessary to make the progress of the ease intelligible. It may be stated that the discharges were carried off entirely through the drainago-tubc, from which they passed in to a receptacle ; that the dressing required to be removed only when it became soiled with urine or freces; and that, by means of a Higginson's syriuge attached to the smaller tube, irrigation was effected without disturbing the patient's posture, sometimes even without her knowledge. The fluid used was simple warm water, unless when it is stated otherwise.

August 15th. At midnight she vomited a large quantity of offensive fluid, after which she passed a comfortable night. Temperature, at 10 A.M., $98.4^{\circ}$. There was a discharge of 5 to 6 ounces of blood. All symptoms of obstruction had disappeared ; the bowels were beginning to act ; an enema was orderel, with the result that they continued to be moved during the rest of the day.

August 16th, 10 A.M. Temperature 98.6 $6^{\circ}$. During twenty-four hours, four or five ounces of blood free from odour had been discharged. The bowels had been moved several times during the night. The nurse had failed to pass the catheter. The dressing and bedclothes were soaked with urine.-9 P.M. Pulse 120, intermittent and shaky. Temperature 99.8 . She had sharp pains in the bowels, though flatus and urine passed freely. Opium was ordered.

August 17 th. Pulse 125 ; temperature $100.4^{\circ}$. She was very restless during the greater part of the night. There was no discharge from the drainage-tube till early Inorning, when over two ounces escaped, after which she felt much relieved. On examination, I found that the tubes, though still in the wound, were withdrawn from the cavity, the explanation being that the nurse had, the previous afternoon, loosened the bandage, because the patient complained of being uncomfortable. On removing the tubes and introducing my finger into the cavity, a considerable quantity of very offensive bloody discharge escaped. The tubes were replaced, and the cavity thoronghly washed out. Irrigation was ordered to be done every two hours. In the evening, the patient was much better. Temporature $98.6^{\circ}$; pulse 108 , steadier and stronger.

August 19th. T'emperature $98.8^{\circ}$. The patient was resting well, and taking nourishment freely. The discharge was still bloody, and now contained a quantity of débris. As the fluid did not flow freely in irrigating, the tubes were withdrawn, and along with them came the umbilical cord and numerous shreds of placenta. Irrigation was ordered to be done every two hours.

August 22nd. The discharge was now free from blood. The tube, being again blocked, was taken out. Introducing my finger into the cavity, I found that the placenta was still adherent, and proceeded cautiously to detach it, which I succeeded in doing without exciting any hrmorrhage. Then, by pressure of the finger, I broke it up, and removed it piecemeal by the aid of a long polypus-forceps. The tubes being reapplied, thorough irrigation with carbolic lotion ( 1 in 40) completed the process, which occupied nearly an hour. The patient, who had not been chloroformed, boing very faint and exhausted, was ordered brandy and opium.

August 23rd. The temperature was normal ; there was no bad symptom of any kind. From this date, the improvement in her general condition was rapid and uninterrupted. The debris that came away in irrigating consisted now unly of small particles without any pus.

September 1st. There had been no hitch of any kind since the last date. There was now no debris, nor fotor, and merely a trace of pus. The patient was allowed to sit up in bed.

September 6th. I found her downstairs, attending to her household duties. The discharge now contained nothing but a little mucus. I withdrew the tubes from the sac, leaving them in the wound for some days, when, as no bad symptom arose, they were finally removed, after which the perineal wound speedily healci.

October 28th. The patient menstruated a fortnight ago in her usual way. There was some rigidity in the left fornix, and a cordlike hardness could be felt along the left vaginal wall in the track of the wound. The uterus occupied its normal position, was movable, and in other respects free from disorder.

Nores. - The following observations upon the tumour and its con. tents during and after the operation may be of interest. The sac, or at least that portion of it which was incised, was contractile. I was conscious of my finger being grasped when introduced into the open. ing made in it, the closure of which, on removal of the finger, was so coinplete, as to cause some difficulty in finding it again. It was also dilatable, as, in extracting the foitus, the wound was not enlarged by rupture. The position of the wound was about the centre of the floor, and afforded the greatest facility for exploration. Internal to it was the placenta, adherent to the floor and inner wall, while the fotus lay in the outer portion. The cavity was oval in shape, with its greatest diameter in the transverse diameter of the pelvis. In cxtracting the fuetus, and on two or three occasions during the operation, there were observed well-marked labour-paius. The footus appeared to be about four months, shrunken and macerated to a moderate degree. Tho placenta was considerably larger than is usual in a four months' pregnancy. The small portion removed for inspection was in the same condition as the futus, and so, no doubt, was the entire fuetal division of it. As the outer border lay close to, if it were not involved in, the incision in the sac, the detachment of a small portion in introducing the tubes explains the harmorrbage that occurred. The wound being about the centre of the floor of the cyst, as has been mentioned, when the finger was inserted at the time of operation, there was an equal division of the cavity internally and externally to it. On September 6th, when the tubes were removed, I took the opportunity of making an examination, whon $I$ found that the external division was entirely obliterated; tho finger lay in contact with the outer wall.

REMARKs. - It appears probable that the attack of obstruction of the bowels was preceded and induced by false labour, the pains of which jammed down the tumour in the pelvis, causing pressure upon the bowel. Perineal section is easy of performance; considered ana. tomically, it is a safe procedure, no important vascular or other structure beiug, with ordinary care, endangered; it affords a direct and dependent routo to the pelvic floor, and is, therefore, woll adapted for the drainage of fluids in that situation. These advan tages might, to a considerable extent, be claimed for vaginal section, which, however, establishes a fistulous communication between the vagina and the tumour, and is in this respect so objectionable as to be seldom practised. In a large number of cases that are amenable to treatment by incision and drainage, as opposed to excision, the tumour is intimately adherent to the pelvic floor, as, for instance, in abscess, pyosalpinx, and hamatocele. It is this condition that makes excision difficult and dangerous, sometimes impossible ; and it is pre cisely the condition that is required for perineal section. Comparing the latter operation with abdoninal section for the purpose of drainage, it would seem to be safer, inasmuch as it does not nocessitate opening into the peritoneal cavity, and is free from the risk attendant upon stitching the sac to the abdominal wall; and it appears to afford a better outlet for discharge.

ON DRAINAGE OF THE BLADDER.

WITH SPECIAL AJPGRENCE TO A POSTPROSTATIC OPERATION. BY E. H. HOWLET'I, F.R.C.S.

Surarows have long been acquainted with different methods of emptying the bladder other than through the urethra. Endeavours have, however, been shiefly directed to the alleviation of immediate troubles, the tiding over till such time as nature shall reassert herself, and remove the temporary obstruction to the flow of urine. Of these methods, the one most in favour is suprapubic aspiration of the bladder, a proceeding generally considered to be both safe and expeditious. Individually, I have the highest opinion of the proceeding, and in any difficult case of retention of urine would rather aspirate the bladder than interfere in any except the most gentle manner with the urethral track; and I venture to think that, were suprapubic aspiration more frequently employed, we should see and hear less of alarming symptoms following the use of the catheter; indeed, it requires but a limited experience to come across cases hurried to an early grave by the too liberal employment of that instrument. As illustrating $m y$ confidence in aspiration, I here incidentally mention the case of a man who called at $m y$ house in December last, in the agonies of acute retention of urine. There was a history of stricture of some years' standing, with a diminished stream on micturition. The obvious cause for the retention was wanting, as the man, at the time of seizure, was following his usual occupation as a clerk. Haring failed to introduce either a soft or a metal catheter through the stricture, and preferring not to meddle much with the urethra in its ex. cited condition, I proceeded to suprapubic puncture, using a small 
needle, and by siphon action withdrew a quantity of rery ammoniacal urine, the probable exciting cause of the urethral spasm. The patient then walked back to his house, and went to bed, and, as no ill effects followed the puncture, I proceeded at leisure to attack the stricture, the spasmodic condition having subsided. There are so few recorded fatalities following suprapubic aspiration (Mr. Treves, of the London Hospital, has recorded one), that I think it my duty to publish one that occurred in my own practice. In January, 1885, a patient who for years had suffered from prostatic troubles, and had been in the habit of relieving himself with a cathoter, was attacked with retention. The practitioner in attendance having failed to relieve symptoms, $m y$ services were called in; and having made a gentle endeavour to pass a catheter unsuccessfully, I performed suprapubic aspiration, drawing off a considerable quantity of ammoniacal urine, which deposited a ropy pus on stunding. The next morning, the operation was reperted, after which time a catheter could be nassed into the bladder. On the following morning, it was evident that some septic element had been inserted at the suprapubic punctures, for an indolent blush was seen to surround them, and to spread in red streaks ovor the abdomen. It is possible that, in withdrawing the needle from the bladder, some of the decomposing urine was inoculated; at any rate, I profer to suspect the condition of the urine rather than that a poison had attacked the wound from without. Every precaution was taken to ensure cleanliness in the instrument, a perfectly new needle, dipped in 1 in 10 carbolic oil, being used. It is needless to relate further details of this case; suffice it to say that the man died, his death being attributable, doubtless, to the small operation.

Continuous drainage of the bladder has hitherto attracted but little attention from the profession; for if we except the practice of Sir Henry Thompson and Mr. Reginald Harrison and 2 fow others, it cannot be said to have been employed in anything like a systematic manner. Chronic cystitis, enlarged prostate, atjny of the bladder, paralytic retention, ruptured urethra, impassable stricture, and malignant diseases of the prostate or bladder, are some of the affections in which continuous drainage might bo employed with success, whilst in plastic operations about the urethra it will bo found invaluable. Dr. Macan has advocated the formation of a vesico-vaginal fistula in the treatment of chronic cystitis in the female ; in other words, "continuous drainage." Surgeons for long enough have been treating chronic cystitis by drainage and antiseptic washes, but I humbly suggest that in so doing they have been attacking the disease from the wrong side. If we desire to irrigate the bladder, what can be more rational than to make use of Nature's irrigators, the kidneys ? Urine, as it flows into the bladder, is in an aseptic condition, but it is readily decomposed by any ferment existing in that viscus. We are able, however, to alter the condition of the urine, so that, instead of a bland aseptic fluid, it will become an active antiseptic one. This can be clone by the administration by the mouth of either boracic acid or salicylate of soda; both drugs answer well, but the boracic acid $(1$ in 20$)$ is, as a rule, better borne than the salicylate. It is often marrellous to watch the effect of the administration of these drugs in some cases of chronic cystitis, for urine, which on being passed has for days and weeks been stinking, in a few hours becomes bland and clear. In this place I may add that, before undertaking any operation on the bladder or urethra (except in cases of emergency) the patient should be placed on a course of one of these drugs for at least three days previously. Many cases of fractured spine with paralytic retention have been hurried to their grave by intractable cystitis, whereas, by a well-timed operation, life might have been prolonged, and recovery of some sort perhaps have taken place.

Assuming, then, that there are conditions which might best be treated by continuous drainage, we have next to consider what method of operating gives the greatest prospect of success. Five methods have been employed, namely, suprapubic, rectal, and interpubic puncture, opening the membranous urethra, and prostatic puncturc. To these I would add a sixth, the postprostatic puncture from the perinæum. The objections to suprapubic and rectal tapping are too obvious to need further discussion. Interpubic puncture is difficult; and, accord. ing to Sir Henry Thompson, by the time the trocar has penetrated the pubic bone, it is too blunt to enter the bladder. Opening the membranous urethra, though strongly advocated by Sir Henry Thompson, has the great disadrantage of interfering with the urinary canal ; whilst Mr. Reginald Harrison's prostatic puncture requires a condition of that body not always obtainable in the class of affections which I have suggested as likely to be benefited by continuous drain. age. The postprostatic operation is free from any and all the objec tions which can be raised against the other operations; it is well placed for drainage, it does not interfere with the genital tract, nor $B$ it in the way in defecation. The part of the bladder attacked is the same as in the rectal operation, the site long since selected by surgeons as most farourable for tapping. On the other hand, the risk of urinary extravasation behind the deep pelvic fascia, of injury to the resiculæ seminales, and to the peritoncum or knuckle of intestine in the recto-vesical pouch, may be urged as disadvantages of the operation. They are, I believe, largely imaginary, as with proper care the dangerous rocks can be avoided; the most real danger is that of urinary extravasation; but, as will be pointed out in the cases to be mentioned, the muscular and mucous coats of the bladder contract immediately after the withdrawal of the instrument, and prevent any urine from escaping, whilst, even should some do so, it will choose the path of least resistance and appear at the perincal puncture. To perform the operation, the patient is placed in the lithotomy position, and if the bladder be contracted, it can be filled from the urethra in most cases. The forefinger of the left hand is then passed into the rectum, and made to explore the prostate and inferior surface of the bladder. Some sort of idea can then be formed of the distance the trocar will have to travel to reach the bladder, and the direction. The forefinger being retained in the rectum, a trocar and cannula, of the size of $\mathrm{No}, 12$ cathetor, is thrust through the skin about three-quarters of an inch in front of the anus, and slowly pushed on till resistance is felt to have disappeared; the trocar is then withdrawn, and the bladder emptied. The subsequent steps of the operation require no description. In my cases, the metal cannula was maintained, but it would be better to pass through it into the bladder a No. 8 red elastic tube, and withdraw the cannula. It is a great advantage to be able to introduce so large a tube, as the chances of its becoming blocked are reduced to a minimum. Finally, to make the patient comfortable, a tube is attached to the catheter, and the urine drained into a bottle. To retain the catheter, Mr. Appleton, of Beverley, devised a very simple apparatus. It consists of a triangular piece of thick leather, with a hole in the centre, through which the catheter passes. One small bole behind, and others at either of the front corners, permit the tapes passing, which are attached to a belt round the loins.

1 will now relate two cases in which this plan of drainage was employed.

A lad, aged 10, the subject of complete epispadias, who had been operated on frequently by Mr. Hardie with considerable success, was udmitted in to the Manchester Royal Infirmary, under the carc of that surgeon, in 1881, for further treatment, there still being some fistulons openings. Mr. Hardie very kindly surrendered the case into my hands (then resident surgical officer). Recognising the importance of keeping urine from any wound, I determined to drain the urine straight from the bladder through the perinæum, and for this purpose first employed the method described above. The operation, as regards the fistulæ, was a failure; but the perineal drain answered the highest expectations, although its performance was rendered more difficalt by the contracted condition of the bladder. A repetition of the operation was not more successful, owing to the patient managing to displacc the cannula. An attempt was immediately made to reinsert it, bat the muscular bladder-walls had contracted and closed the opening, so that it was necessary to repuncture with the trocar. The size of the instrument was equal to a No. 6 catheter, and the cannula was retained in position by horsehair stitches, through the skin of the perinzum, a suggestion of Mr. G. A. Wright, who assisted at the operation. Two points were prominently forced on my mind by this case : firstly, the great advantage of a perineal drain ; and, secondly, the slight risks of urinary extravasation. So satisfactory did I consider the method of drainage, that I determined, should any case come under my care in which drainage was required, to again put this method in practice; but it was not till July, 1885, that a suitable case presented itself. This was one of slight prostatic enlargement, with a feeble dilated bladder. The man was under the care of Mr. Appleton, of Beverley, who had on different occasions treated him for retention and blodder-trouble, and, at his request, I examined the patient. Nothing but a catheter life was before him; but, taking into consideration the feeble power of the bladder, and that soon an aggravated condition of affairs might be expected, I did not hesitate to urge the expediency of some more energetic proceeding. The patient consenting, and Mr. Appleton having administered tho anæsthetic, the postprostatic puncture was carried out, the large No. 12 trocar being employed. The cannula was left in situ, my intention being to retain it for ten days, and then replace it by a rabber tube. Next day the condition of the patient was fairly satisfactory, urine draining away by the cannula ; but considerable pain was felt, and referred by the patient to the tip of the penis.

During the next two days, the drainage at times ceased to act, owing probably to the superior wall of the bladder obstructing the orifice of the cannula, the cause also of the pain at the end of the 
penis. On the fourth day after the operation, the patient was in a most unsatisfactory condition, and had a rigor; he complained also greatly of the pressure of the tube in the bladder. Suspecting that the thrust of the rigid tube, projecting into the bladder and against its upper wall, was setting up ulceration, I reluctantly withdrew it. From this time the general condition improved, owing to the assiduous care of Mr. Appleton, so that, a week later, I felt justified in endeavouring to reopen the perineal route. An olive.pointed No. 6 catheter, to my surprise, after a little persuasion, entered the bladder; but there being objections to any unnecessary projection into the bladder, it was withdrawn, and a soft red elastic No. 8 tube was passed in its place, being retained in the ordinary mothod. Recovery was uninterrupted. and in December I had the satisfaction of exhibiting the patient at the meeting of the local Branch of our Association. Ho was then wearing the perineal tube, the outside portion of which was clamped and fixed to a belt round the waist. The patient is now able to micturate at will, without any trouble. During the night, instead of draining into a vessel, he prefers to get up once or twice and turn on the tap, a much simpler operation than micturating. $\mathrm{He}$ has gained three-quarters of a stone in weight, and altogether expresses himself as being in a more comfortable condition than he has been for months past, that is, before the operation. I made an examination in December of both prostate and bladder, but could not satisfy mysclf that any marked change had taken place in either organ.

In a case of prostatic puncture, recorded by Mr. Harrison, a decided reduction in the prostate took place after wearing the tube for over two months, a change which Mr. Ilarrison regards as analogous to that occurring in the prostate of elderly persons after lithotomy. It may be also partly due to a subsidence of the engorgement which takes plaze in enlarged prostates during the repeated efiorts at micturition. In cuses in which the prostate is enormously hypertrophied, it is obvious that there is no room to perform the postprostatic puncture, and any attempt to carry it out would resolve itself into Mr. Harrison's operation. The case above related shows the disadvantage of retaining the solid cannula in the bladder, and it is for this reason that I advise the immediate passage of a large sized soft tube through the cannula, and the withdrawal of the rigid tube ; also that, in atonic conditions of the bladder, it is the falling together and possible sliding of the mucous lining, and not simply the muscular walls, that prevents the outward passage of urinc. I regret very much that my opportunities of carrying out the operation of postprostatic puncture are very limited, that I cannot bring forward a large number of cases illustrating its employment in the aforementioned discases; but believe $I$ have succeeled in placing before the profession a novel and simple method of operating, which, if carried out on the lines indicated, may be the means of saving or prolonging life, and I trust that there may be some who will be induced to try, and report on, the operation.

\section{REMARKS ON INCONTINENCE OF URINE IN CHILDREN.}

By WILLIAN H. DAY, M.D.,

Physician to the Samaritan Hospital for Diseases of Women and Children.

THERE is scarcely any disease occurring among children more annoying and troublesome than incontinence of urine. It is particularly vexatious to parents, and is often regarded by them as an incurable infirmity. After their patience has been long tried, they abandon ono remedy after another, and look forward to puberty, when, they are told, the discaso may depart never to return. Failure in treatment is frequently owing (1) to an erroneous diagnosis of the cause of the affection ; (2) to the incficiency with which the treatment is carried out ; (3) to its being discontinued too soon ; hence, in hospital practice, where patients can be watched, we meet with better results than in private practice.

Among the causes of enuresis, the following may be enumerated. If the urine be excessively acid, or loaded with urates, the bladder becomes overstimulated, and readily discharges its contents. If the bowels be habitually costive, or there be worms in the intestines, vesical irritation may ensue ; or, if the child be guilty of masturbation, there will be no chance of eure till the habit is corrected. Weakness of the muscular coat of the bladder from general debility or anæmia is a very com:non cause ; the bladder, not being able to tolerate any quantity of urinc, readily excites the motor apparatus. I have known a troublesome case follow typhoid fever in a boy, 10 years of age. If the disease be owing to a long prepuce, causing phimosis, it should be removed. Sometimes no cause can be ascertained. Child. ren, two or three years of age, frequently wet the bed, either from laziness, or from lack of control over the blacluer. It is important to remember that, even though the secretions are in perfect order, the incontinence may continue ; and thus a habit may be formed, which the poorer classes and stern people occasionally endeavour to correct by punishment. In some idle and dirty children, such a course may be of benefit; but in others, who are nervous and timid, there is the possibility of increasing the evil we desire to remove. I make no allusion to those cases of enuresis associated with diseaso of the bladder or brain.

Enuresis is sometimes seen in connection with chronic albuminuria, and is occasionally so persistent as to require special treatmont. The following is a good illustration.

CASE 1.-G. M., aged 9, was sent to me from the country, April 4th, 1885. His bed was wet both night and day. Before he was 6 year's of age, he had measles and whooping-cough; then, after a short in. terval, scarlet fever, followed by dropsy. $\Lambda$ year after his recovery from the dropsy, he could only pass his urine in drops. "He would stand up and cry, and say he wanted, and could not." Ho suffered in this way for two months, and then he would pass urine every ten minutes, but without pain. Some time before he left his home in the country, he was tested for stone in the bladder, as he frequently had pain, and blood was occasionally present in the urine. The urine, on admission into hospital, was highly albuminous (one-tenth part), of specific gravity 1020, pale, cloudy, and of acid reaction. A few casts were seen under the microscope. There was no fever, nor carliac disturbance. He was confined to bed, and, as he had pain across the lumbar region, he lay during a part of the day on his abclomen, to lessen local congestion. He was ordered a milk-diet, and a mixture of belladonna, nux vomica, and tincture of perchloride of iron three times a day. Four days after admission, he ceased to wet himself in the daytime, and on the 10th, 11th, and 12th he was dry at night. The bowels were kept open, and the albumen diminished. On the 30 th, it was reported that he had not wetted the bed since the 14th. He passed a much less quantity of urine, but it was still albuminous. He went home, after staying in the hospital for six weeks, wonderfully relieved, his urine only containing a trace of albumen, and no blood-corpuscles. In November, I heard that the frequency in micturition had returned, that he was worse in cold weather, and that the urine was very albuminous. I have mentioned this case merely to show that the treatment, which mainly consisted in a milk-diet and attention to hygienic conditions, had for a time a very salutary effect. CASE Ir. - E. F., aged 7, was admitted into the Samaritan Hospital under my care November 3rd, 1884. The patient was a twin, highly nervous and excitable, with mitral disease, jrobably congenital. She never had scarlet fever or rheumatic fever. She first began to ail fifteen months before admission, wanting to pass urine frequently. She wetted the bed every night; the urine was pale, copious, and contained phosphates, specific gravity 1020, acid. A solution of nitrate of silver was applied to the neck of the bladder (two scruples to one ounce), and for a few days it seemed to be of benefit. A mixture of tincture of belladonna and tincture of perchloride of iron was ordered three times a day, but $n$ good result followed; and on December 1st I began to employ Stohrer's smallest induction-apparatus (interrupted current) with one closed cell, for ten minutes daily, one sponge being placed over the sacrum, and the other over the pubes. An improvement almost immediately set in, and the patient left the hospital cured on January 10th, 1885. She was readmitted into hospital on September 30 th, 1885 , suffering from general debility and pain over the cardiac region, but she had no return of the enuresis whilst she remained in the hospital for six weeks. This is the second case I have recently seen associated with heart-disease.

CASE III. - G. R., aged 7, was admitted into the Samaritan Hos pital under my care November 27 th, 1884 . For upwards of eighteen months, he had wetted the bed at night, and frequently during the day. The mother fancicd that he had been tamperel with by some boys of his own age. The urine was very pale, of acid reaction, and contained a few phosphates. He was ordered a nilk-diet, and meat once a day. Faradisation was used daily for ten minutes. He took a mixture of tincture of belladonna and tincture of perchloride of iron three times a day, and left the huspital cured on January 9th, having wetted his bed only five times since his admission, and some of these nights very slightly.

CASE IV.-A. H., aged 8, a pale and irritable boy, was born in South America, a healthy baby. Ile had incontinence of urine from birth. When brought to me on December 13th, 1884, he wetted himself both night and day, and was invariably wet after being in bed ten minutes. He passed large quantities of high-coloured offensive urine, containing unch uric acid. When the urine had become 